\title{
A Research on a Double Auxiliary Resonant Commutated Pole Soft-Switching Inverter
}

\author{
Liang Huang, Enhui Chu, and Xing Zhang
}

\begin{abstract}
Aiming at overcoming the problem that the auxiliary switches in an improved auxiliary resonant communicated pole inverter may not realize zero-voltage turning off in practical application if there are parasitic inductors in the wiring process, this paper proposes a novel double auxiliary resonant commutated pole inverter. In novel topology, auxiliary capacitance and auxiliary switch are in parallel. This structure avoids the influence of parasitic inductors in the wire, and ensures the auxiliary switch to realize zero-voltage turning off reliably. The novel topology not only inherits all advantages of the improved auxiliary resonant communicated pole inverter, but also improves its reliability. Therefore the novel topology is more suitable for high power occasion.
\end{abstract}

Index Terms-Soft switching, double auxiliary resonant commutated pole inverter, parasitic inductance, reliability.

\section{INTRODUCTION}

In recent years, with the development of power electronics technology, the applications of soft-switching technology play an important role in high-frequency PWM inverters [1]-[4]. Among many inverter topologies, the auxiliary resonant inverter is an important type, which mainly includes resonant DC link inverters [5], resonant AC link inverters [6] and auxiliary resonant commutated pole inverters. Auxiliary resonant commutated pole inverters do not increase voltage and current stress of main switches, so they are more suitable for high-power occasions.

The traditional active auxiliary resonant commutated pole (ARCP) inverter [7] has two bulk capacitors, and the electric potential in neutral point is variable. Moreover, it need separate detecting circuits and logic control circuits, which lead to control circuits are very complicated. Although many improved ARCP inverters [8]-[11] solve the two bulk capacitors problem subsequently, they need either complex coupled inductors or transformers with corresponding magnetic flux reset circuits. Furthermore, the three single-phase resonant circuits of some inverters are coupled with each other. In addition, in order to achieve soft switching, some topologies also need additional detecting circuits and peripheral logic circuits. So the main circuit and control circuits will be very complicated.

Manuscript received November 7, 2013; revised March 5, 2014. Date of current version is December 10, 2013. This work was supported by the Fundamental Research Funds for the Central Universities under Grants N100404015

The authors are with the College of Information Science and Engineering, Northeastern University, Shenyang 110819, China (e-mail: huangliang_90@163.com; 15840219515@163.com).
Then, an improved ARCP inverter with the function of pulse current regeneration is proposed in reference [12]. This topology not only avoids using two bulk capacitors, but also eliminates the neutral point potential variation. In addition, the three single-phase auxiliary commutation circuits in this topology are independent of each other, and they can be applied various modulation strategies easily. However, when considering the presence of parasitic inductors in the wiring process, there may be voltage spikes during the auxiliary switches turn off. So, the auxiliary switch cannot realize zero-voltage turning off reliably. The reliability of this topology is low.

To solve this problem, this paper proposes a novel topology with double auxiliary resonant commutated pole. By using the method of the auxiliary capacitor paralleling with the auxiliary switch directly, it is avoided that the influence of parasitic inductors in the wire. The novel topology not only inherits all advantages of the topology proposed in reference [12], but also assures that the auxiliary switch can realize zero-voltage turning off reliably when considering the presence of parasitic inductors in the wiring process. So the reliability of novel topology will be improved significantly.

\section{TOPOLOGY AND MOdUlation STRATEGY}

The novel topology is shown in Fig. 1. Since the structures of three single-phase auxiliary resonant circuits are identical and independent, they can be modulated by themselves. So one phase leg of the inverter is analyzed in this paper.

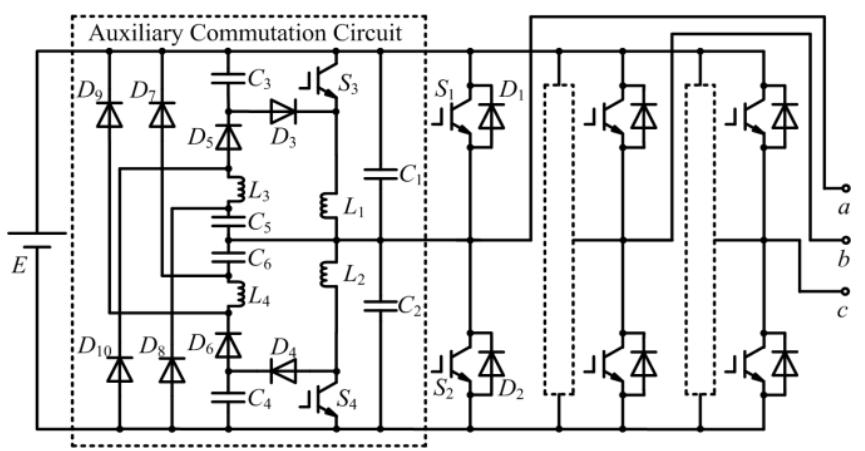

Fig. 1. The novel topology.

The auxiliary commutation circuit of the inverter is composed of auxiliary switches $\left(S_{3}, S_{4}\right)$, main resonant capacitors $\left(C_{1}, C_{2}\right)$, first resonant capacitors $\left(C_{3}, C_{4}\right)$, second resonant capacitors $\left(C_{5}, C_{6}\right)$, first resonant capacitors $\left(L_{1}, L_{2}\right)$, second resonant capacitors $\left(L_{3}, L_{4}\right)$, resonant diodes $\left(D_{3}, D_{4}\right)$, $\left(D_{5}, D_{6}\right),\left(D_{7}, D_{8}\right),\left(D_{9}, D_{10}\right)$. During the turn-on period of main switch $S_{1}\left(S_{2}\right)$, the voltage across main resonant capacitor $C_{1}\left(C_{2}\right)$ is zero. When main switch $S_{1}\left(S_{2}\right)$ is turned 
off, main resonant capacitors $C_{1}, C_{2}$ and first auxiliary resonant capacitor $C_{3}\left(C_{4}\right)$ will limit the voltage change rate of main switch $S_{1}\left(S_{2}\right)$ and provide zero-voltage-switching (ZVS) turn-off condition to $S_{1}\left(S_{2}\right)$. When auxiliary switch $S_{4}\left(S_{3}\right)$ is turned on, the current through first auxiliary resonant inductor $L_{2}\left(L_{1}\right)$ increases from zero and the auxiliary switch $S_{4}\left(S_{3}\right)$ realizes zero-current-switching (ZCS) turning on. When auxiliary switch $S_{3}\left(S_{4}\right)$ is turned off, the voltage across second auxiliary resonant capacitor $C_{5}\left(C_{6}\right)$ increases from zero and the auxiliary switch $S_{3}\left(S_{4}\right)$ realizes ZVS turning off. Besides, the energy stored in auxiliary resonant inductor $L_{1}\left(L_{2}\right)$ begins to transform to the auxiliary resonant capacitor $C_{3}\left(C_{4}\right)$. Until the voltage across first auxiliary resonant capacitor $C_{3}\left(C_{4}\right)$ is charged to input DC voltage $\mathrm{E}$, the residual energy stored in the first auxiliary resonant inductor $L_{1}\left(L_{2}\right)$ is fed back to DC power supply by the energy regeneration feedback diode $D_{9}$ $\left(D_{10}\right)$.

The modulation strategy is shown in Fig. 2. In sine-wave triangular-comparison pulse width modulation (PWM) with dead time, the operation sequence is designed as the on and off periods of main switches, which are alternated at intervals of $\pi$. The dead time is $\delta_{t 1}$. At the moment of turning off main switch $S_{1}\left(S_{2}\right)$, turn on auxiliary switch $S_{4}\left(S_{3}\right)$ immediately. Since the moment of turning on main switch $S_{2}\left(S_{1}\right)$, it is prolonged for $\delta_{t 2}$, and then turn on auxiliary switch $S_{4}\left(S_{3}\right)$.

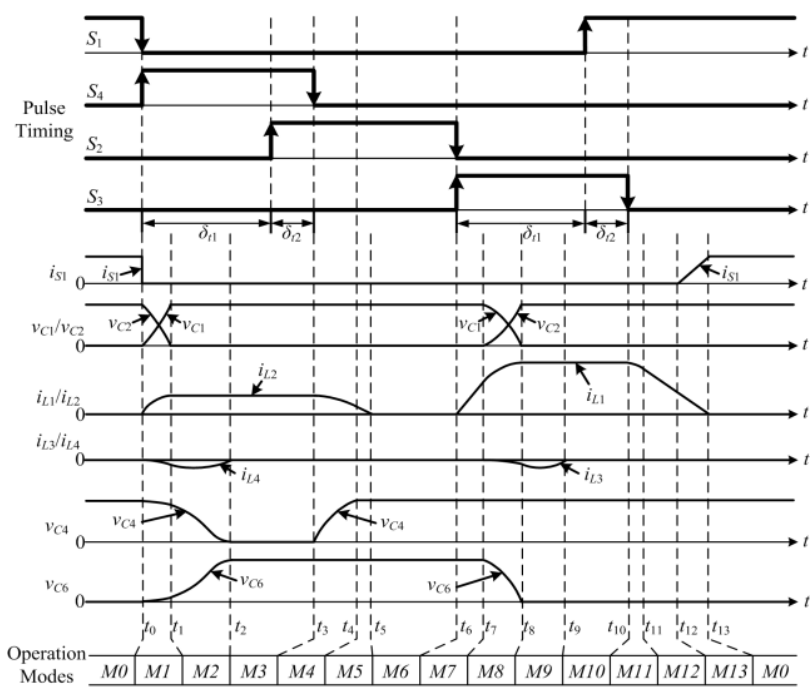

Fig. 2. Modulation strategy and key theoretical waveforms.

\section{OPERATIONAL PRINCIPLE}

In order to facilitate the analysis, several assumptions are employed:

1) All switches, diodes, capacitors and inductors are ideal devices.

2) The values of main resonant capacitors $\left(C_{1}, C_{2}\right)$ are $C_{1}=C_{2}=C_{a}$. The values of first auxiliary resonant capacitors $\left(C_{3}, C_{4}\right)$ are $C_{3}=C_{4}=C_{b}$. The values of second auxiliary resonant capacitors $\left(C_{5}, C_{6}\right)$ are $C_{5}=C_{6}=C_{c}$. The values of first auxiliary resonant inductors $\left(L_{1}, L_{2}\right)$ are $L_{1}=L_{2}=L_{a}$. The values of second auxiliary resonant inductors $\left(L_{3}, L_{4}\right)$ are $L_{3}=L_{4}=L_{b}$.

3) Since the switching frequency $f_{s}$ is much larger than the output current/voltage frequency $f_{o}$, the load current $I_{a}$ is constant during one commutation processes. The reference positive direction of the load current is the same as the direction of the arrow in Fig. 3.

The key theoretical waveforms of novel topology are shown in Fig. 2, and the equivalent circuits of different operation modes are shown in Fig. 3.
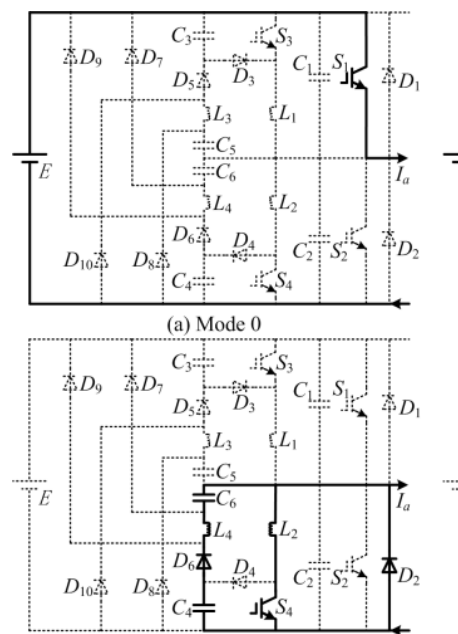

(c) Mode 2
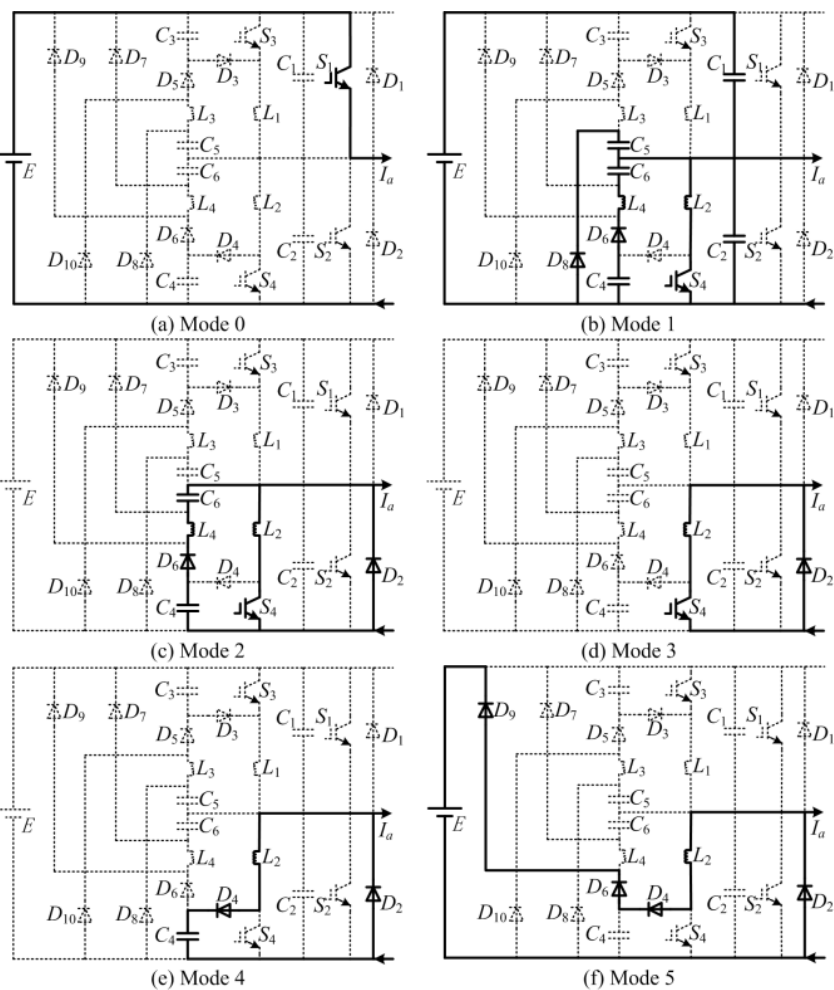

(d) Mode 3

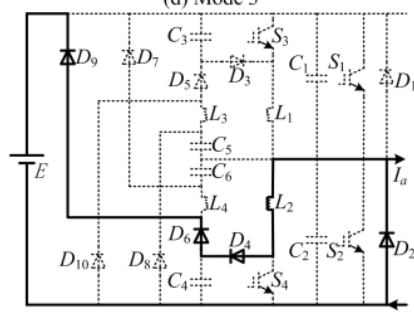
(e) Mode 4
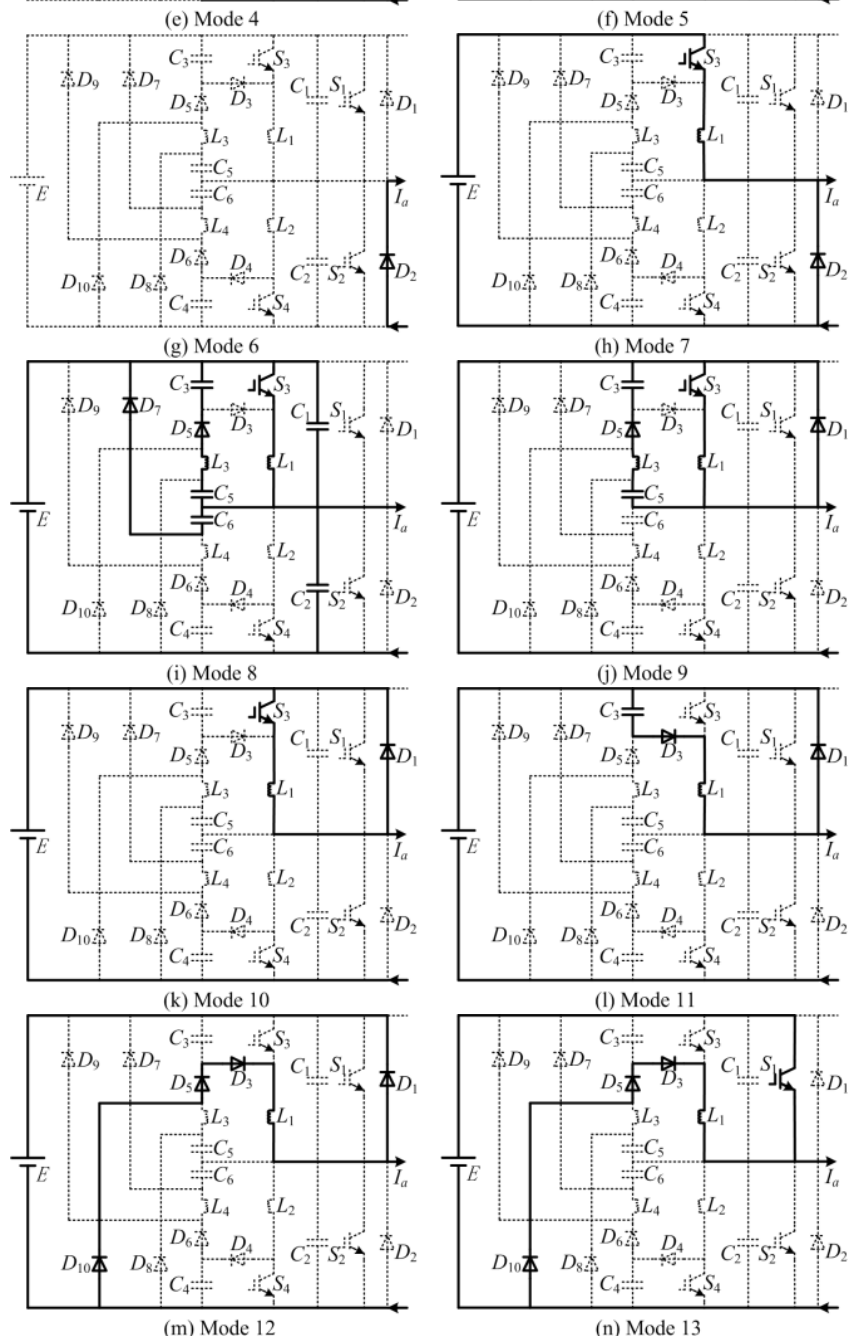

(n) Mode 13

Fig. 3. Single-phase equivalent circuits of different operation modes 
The operation modes are analyzed in detail as follows:

Mode $0\left[\sim t_{0}\right]$ : Before $t_{0}, S_{1}$ is in the turn-on state and $S_{2}, S_{3}$, $S_{4}$ are in the turn-off state. This mode is the stable state that $S_{1}$ carries load current. Where $v_{C 1}=v_{C 6}=0, v_{C 2}=v_{C 3}=\mathrm{E}, v_{C 4}=v_{C 5}=E$, $i_{S 1}=I_{a}$.

Mode $1\left[t_{0}, t_{1}\right]$ : At instant $t_{0}, S_{1}$ is turned off and the load current $I_{a}$ is commutated to $C_{1}, C_{2}$ and $C_{5}$ immediately. $C_{1}, C_{2}$, $C_{5}$ and $L_{2}$ begin to resonate. The voltages across $C_{2}$ and $C_{5}$ fall from $E$. The voltage across $C_{1}$ rises from zero. $S_{1}$ is ZVS turn-off. The current through $L_{2}$ rises from zero. $S_{4}$ is ZCS turn-on. At the same time, $C_{4}, C_{6}$ and $L_{4}$ begin to resonate. The voltage across $C_{4}$ falls from $E$. The voltage across $C_{6}$ rises from zero. When the voltage across $C_{1}$ rises to $E$, mode 1 ends.

Mode $2\left[t_{1}, t_{2}\right]$ : At instant $t_{1}$, the current through $L_{2}$ reaches to the maximum value $i_{L 2 \max }$. The voltage across $C_{1}$ is charged to $E$ and the voltages across $C_{2}$ and $C_{5}$ are discharged to zero. Diode $D_{8}$ turns off naturally. Diode $D_{2}$ starts conducting and the load current $I_{a}$ is commutated to $D_{2}$ immediately. $C_{4}, C_{6}$ and $L_{4}$ continue to resonate. The voltage across $C_{4}$ falls down and the voltage across $C_{6}$ rises up. Because the voltage across $L_{2}$ is zero and invariable, the current through $L_{2}\left(i_{L 2 \max }\right)$ is invariable during this mode. When the current through $L_{4}$ falls to zero, mode 2 ends.

Mode $3\left[t_{2}, t_{3}\right]$ : At instant $t_{2}$, the voltage across $C_{4}$ falls to zero, and the voltage across $C_{6}$ rises to $E$. Diode $D_{6}$ turns off naturally. The resonant current flows through the series circuit $\left(L_{2}-S_{4}-D_{2}\right)$. The current through $L_{2}\left(i_{L 2 \max }\right)$ is invariable. If $S_{2}$ is turned on during this mode, it is ZVS turn-on. When $S_{4}$ is turned off, mode 3 ends.

Mode $4\left[t_{3}, t_{4}\right]$ : At instant $t_{3}, S_{4}$ is turned off. $L_{2}$ and $C_{4}$ begin to resonant. The voltage across $C_{4}$ rises from zero. $S_{4}$ is a ZVS turn-off. When the voltage across $C_{4}$ rises to $E$, mode 4 ends.

Mode $5\left[t_{4}, t_{5}\right]$ : At instant $t_{4}$, the voltage across $C_{4}$ rises to $E$. Diode $D_{8}$ and $D_{9}$ start conducting. The residual energy stored in $L_{2}$ is feedback to the input DC power supply through $D_{4}, D_{8}$ and $D_{9}$. When the current through $L_{2}$ falls to zero, mode 5 ends.

Mode $6\left[t_{5}, t_{6}\right]$ : At instant $t_{5}$, the current through $L_{2}$ falls to zero, the load current $I_{a}$ flows through $D_{2}$ and the value of $I_{a}$ is invariable.

Mode $7\left[t_{6}, t_{7}\right]$ : At instant $t_{6}, S_{3}$ is turned on. Since $D_{2}$ is conducting, the voltage across $L_{1}$ is $E$. So the current through $L_{1}$ rises linearly from zero. At the same time, the current through $D_{2}$ falls linearly from $I_{a}$. The load current $I_{a}$ is commutated from $D_{2}$ to $L_{1}$ gradually. After $S_{3}$ is turned on, the current through $L_{1}$ rises from zero and $S_{3}$ is ZCS turn-on. When the current through $L_{1}$ reaches to $I_{a}$, the current through $D_{2}$ falls to zero. $D_{2}$ turns off naturally and mode 7 ends.

Mode $8\left[t_{7}, t_{8}\right]$ : At instant $t_{7}, D_{2}$ turns off, and $C_{1}, C_{2}, C_{6}$ and $L_{1}$ begin to resonant. The voltages across $C_{1}$ and $C_{6}$ fall from $E$. The voltage across $C_{2}$ rises from zero. The current through $L_{2}$ rises from zero. At the same time, $C_{3}, C_{5}$, and $L_{3}$ begin to resonate. The voltage across $C_{3}$ falls from $E$. The voltage across $C_{5}$ rises from zero. When the voltage across $C_{2}$ rises to $E$, mode 8 ends.

Mode $9\left[t_{8}, t_{9}\right]$ : At instant $t_{8}$, the current through $L_{1}$ reaches to the maximum value $i_{L 1 \max }$. The voltage across $C_{2}$ is charged to $E$ and the voltages across $C_{1}$ and $C_{6}$ are discharged to zero. Diode $D_{1}$ start conducting and the load current $I_{a}$ is commutated to $D_{1}$ immediately. $C_{3}, C_{5}$ and $L_{3}$ continue to resonate. The voltage across $C_{3}$ falls and the voltage across $C_{5}$ rises. Because the voltage across $L_{1}$ is invariable, the current through $L_{1}$ is $i_{L 1 \text { max }}$ and invariable during this mode. When the current through $L_{3}$ falls to zero, mode 9 ends.

Mode $10\left[t_{9}, t_{10}\right]$ : At instant $t_{9}$, the voltage across $C_{3}$ falls to zero, and the voltage across $C_{5}$ rises to $E$. Diode $D_{5}$ turns off naturally. The resonant current flows through the series circuit $\left(L_{1}-S_{3}-D_{1}\right)$. The current through $L_{1}\left(i_{L 1 \max }\right)$ is invariable. If $S_{1}$ is turned on during this mode, it is ZVS turn-on. When $S_{3}$ is turned off, mode 10 ends.

Mode $11\left[t_{10}, t_{11}\right]$ : At instant $t_{10}, S_{3}$ is turned off. $L_{1}$ and $C_{3}$ begin to resonant. The voltage across $C_{3}$ rises from zero. $S_{3}$ is ZVS turn-off. When the voltage across $C_{3}$ rises to $E$, mode 11 ends.

Mode $12\left[t_{11}, t_{12}\right]$ : At instant $t_{11}$, the voltage across $C_{3}$ rises to $E$. Diode $D_{5}$ and $D_{10}$ start conducting. The residual energy stored in $L_{1}$ is feedback to the input DC power supply $E$ through $D_{3}, D_{5}$ and $D_{10}$. When the current through $L_{1}$ falls to $I_{a}$, mode 12 ends.

Mode $13\left[t_{12}, t_{13}\right]$ : At instant $t_{12}$, the current through $L_{1}$ falls linearly to $I_{a}$. Diode $D_{1}$ turns off naturally. The current through $S_{1}$ rises linearly from zero. The load current $I_{a}$ is commutated from $L_{1}$ to $S_{1}$ gradually. When the current through $L_{1}$ falls to zero, mode 13 ends. At the end of this mode, a switching cycle is achieved.

On the basis of the analysis mentioned above, in mode 4 (mode 11), because the first auxiliary capacitor $C_{4}\left(C_{3}\right)$ is parallel with the auxiliary switch $S_{4}\left(S_{3}\right)$ directly, the auxiliary switch can realize ZVS turn-off reliably. Especially when there are parasitic inductors in the wiring process, due to the presence of the auxiliary capacitor, the process of auxiliary switch turning off will not be affected.

However, for the topology in reference [12], the auxiliary switch is not parallel with a capacitor. So the auxiliary switch just realizes ZVS turn-off condition through mathematical methods according to Kirchhoff's voltage law. The equations will be not right, if there are parasitic inductors in the wiring process. So, the voltage across $S_{4}\left(S_{3}\right)$ is not equal to that across $C_{4}\left(C_{3}\right)$. Therefore, it is not sure that the voltage across $S_{4}\left(S_{3}\right)$ rises from zero. $S_{4}\left(S_{3}\right)$ does not realize ZVS turning off. Moreover, there are voltage spikes probably when $S_{4}\left(S_{3}\right)$ is turned off. The reliability cannot be assured.

\section{Simulation AND EVAluation}

The parameters of simulation are shown below. The nominal of output power is $1.8 \mathrm{~kW}$ and the nominal of output line voltage is $50 \mathrm{~V}$. The output frequency is $50 \mathrm{~Hz}$ and the switching frequency is $16 \mathrm{kHz}$. The input DC voltage is $100 \mathrm{~V}$. The value of main resonant capacitor $\left(C_{1}, C_{2}\right)$ is $100 \mathrm{nF}$, the value of first auxiliary resonant capacitor $\left(C_{3}, C_{4}\right)$ is $50 \mathrm{nF}$ and the value of second auxiliary resonant capacitor $\left(C_{5}, C_{6}\right)$ is $50 \mathrm{nF}$. The value of first auxiliary resonant inductor $\left(L_{1}, L_{2}\right)$ is $2 \mu \mathrm{H}$. The value of second auxiliary resonant inductor $\left(L_{3}, L_{4}\right)$ is $20 \mu \mathrm{H}$. The delay time $\delta_{t 1}$ is $4 \mu \mathrm{s}$, and $\delta_{t 2}$ is $0.5 \mu \mathrm{s}$. The simulation results are shown in Fig. 4.

Fig. 4 (a) shows the wave forms of current and voltage at the moment of turning off the main switch $S_{1}$ and the main switch $S_{1}$ achieves ZVS turning off. Fig. 4 (b) shows the wave 
forms of current and voltage at the moment of turning on the main switch $S_{1}$ and the main switch $S_{1}$ achieves ZCZVS turning on. Fig. 4 (c) shows the wave forms of current and voltage at the moment of turning on the auxiliary switch $S_{3}$ and the auxiliary switch $S_{3}$ achieves ZCS turning on. Fig. 4 (d) shows the wave forms of current and voltage at the moment of turning off the auxiliary switch $S_{3}$ and the auxiliary switch $S_{3}$ achieves ZVS turning off. Fig. 4 (e) shows the wave forms of current and voltage at the moment of turning on the auxiliary switch $\mathrm{S}_{4}$ and the auxiliary switch $\mathrm{S}_{4}$ achieves ZCS turning on. Fig. 4 (f) shows the wave forms of current and voltage at the moment of turning off the auxiliary switch $S_{3}$ and the auxiliary switch $S_{3}$ achieves ZVS turning off.
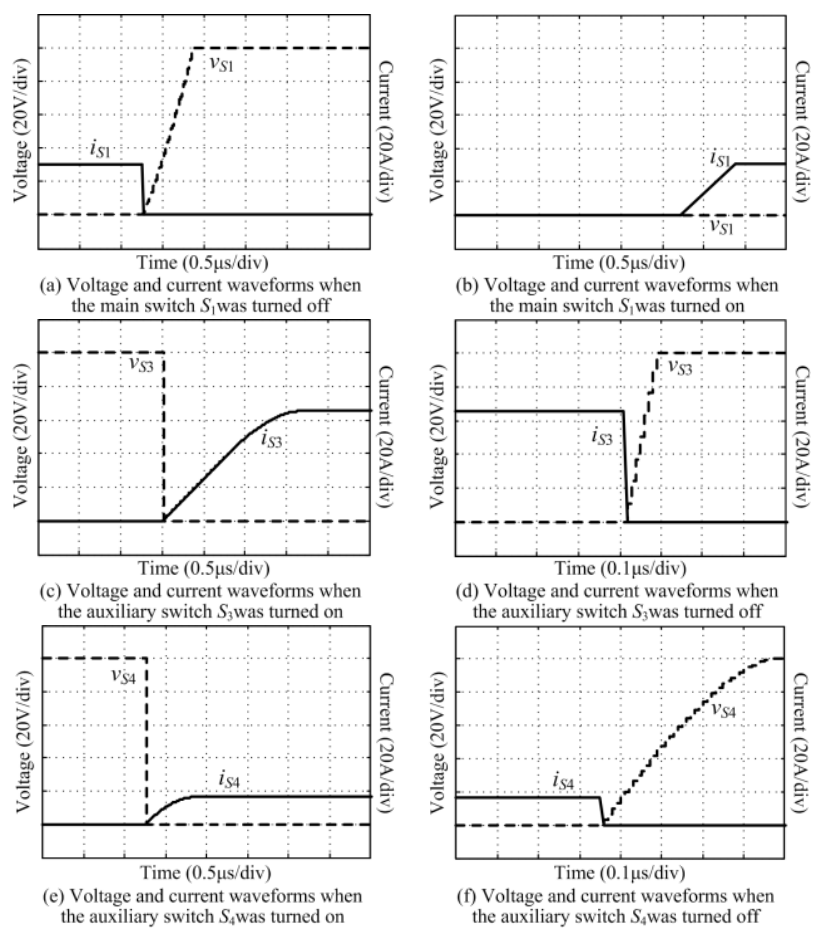
the main switch $S_{1}$ was turned on
oltage and current waverms

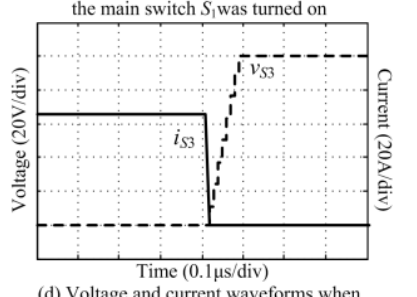
d) Voltage and current waveforms when the auxiliary switch $S_{3}$ was turned off

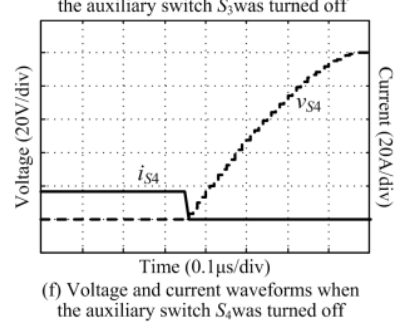
(f) Voltage and current waveforms when
the auxiliary switch $S_{4}$ was turned off nwitch $S_{1}$ and auxiliary switch $S_{3}$ and $S_{4}$

\section{CONCLUSION}

This paper proposes a novel topology. Through the theoretical analysis and simulation results, several conclusions have been got as below:

1) The detecting circuits and logic control circuits are not necessary and all main switches and auxiliary switches can realize ZVS or ZCS turning on and turning off. This is beneficial to increase the switching frequency.

2) The voltage stresses of devices are limited to no more than the input DC voltage E. This is beneficial to select devices.

3) The energy in auxiliary circuit can feed back to the input DC power supply. This is beneficial to improve the energy conversion efficiency.

4) The three single-phase auxiliary commutation circuits are independent of each other, and they can be applied various modulation strategies easily.

5) It is assured that both the main switch and the auxiliary switch can realize ZVS turning off reliably, when there are parasitic inductors in the wiring process in practical application. So the reliability will be improved significantly.

\section{REFERENCES}

[1] M. Luigi, M. Paolo, R. Leopoldo, T. Paolo, M. Walter, and P. Alberto, "Electronic welder with high-frequency resonant inverter," IEEE Trans. on Industry Appl., vol. 31, no. 2, pp. 273-279. Mar. 1995.

[2] C. Rizet et al., "Efficiency improvement in soft-switching three-level converters for high power UPS," in Proc. IEEE Conf. on Energy Conversion Congress and Exposition, Sept. 2010, pp. 1585-1590.

[3] M. Pakdel, "A new soft-switched three-phase four-wire shunt active power filter," in Proc. IEEE Conf. on Vehicle Power and Propulsion, Harbin, China, Sept. 2008, pp. 1-7.

[4] M. Amirabadi, A. H. Toliyat, and W. C. Alexander, "A multi-input AC link PV inverter with reduced size and weight," in Proc. Applied Power Electronics Conference and Exposition, 2012, pp. 389-396.

[5] G. Venkataramanan and D. M. Divan, "Control of pulse width modulated resonant DC link inverter," in Proc. IEEE Industry Applications Society Annual Meeting, Oct. 1992, vol. 1, pp. 737-743.

[6] H. Hayasaka et al., "A method for improving output current waveform of series-resonant AC link inverter," in Proc. IEEE Power Conversion Conference, Yokohama, Japan, Apr. 1993, pp. 233-237.

[7] W. McMurray, "Resonant snubbers with auxiliary switches," in Proc. IEEE Industry Appl. Soc. Annual Meeting, 1989, vol. 1, pp. 829-834.

[8] X. Yuan et al., "Analysis, designing and experimentation of a transformer-assisted PWM zero-voltage switching pole inverter," IEEE Trans. on Power Electronics, vol. 15, no. 1, pp. 72-82. 2000.

[9] J. L. Russi et al., "Coupled- filter-inductor soft-switching techniques: principles and topologies," IEEE Trans. on Industrial Electronics, vol. 55, no. 9, pp. 3361-3373. Sept. 2008.

[10] J. S. Lai, R. M. Young, G. W. Ott, J. W. Mc. Keever, and F. Z. Peng, "A delta-configured auxiliary resonant snubber inverter," IEEE Trans. on Industry Applications, vol. 32, no. 3, pp. 518-525, May. 1996.

[11] J. S. Lai, "Practical design methodology of auxiliary resonant snubber inverters," in Proc. IEEE Power Electronics Specialists Conference, Baveno, Italy, June. 1996, vol. 1, pp. 432-437.

[12] M. Nakamura et al., "A novel prototype of auxiliary edge resonant bridge leg link snubber- assisted soft-switching sine-wave PWM inverter," Electrical Engineering in Japan, vol. 155, no. 4, pp. 64-76, June 2006.

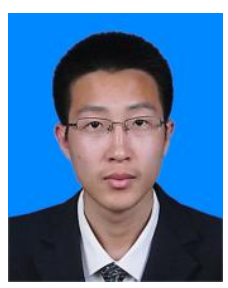

Liang Huang was born in Liaoning Province, China, in 1990. He received the B.S. degree in electrical engineering and automation from Northeastern University, Shenyang, China, in 2013, where he is currently working toward the M.S. degree in electrical engineering. His current research interests include high-performance inverters and soft-switching techniques.

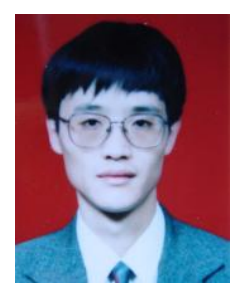

Enhui Chu was born in Liaoning Province, China, in 1967. He received the M.S. degree in automation from Northeastern University, Shenyang, China, in 1993 and the Ph.D. degree in electrical engineering from Yamaguchi University, Yamaguchi, Japan, in 2002. From 1997 to 1999, he was a visiting scholar and a researcher at Yamaguchi University, Yamaguchi, Japan. From 2003 to 2006, he was a researcher in Yutaka Electric Mfg. Co., Ltd. of Nippon Steel \& Sumitomo Metal Corporation, Since 2006, he has been with the College of Information Science and Engineering, Northeastern University, Shenyang, China, where he is currently an Associate Professor. So far, he has been working on power electronics and its applications. His research interests include power converters, medical electronics, autoelectronics, soft-switching techniques, and the application of soft-switching techniques in renewable energy power conversion systems.

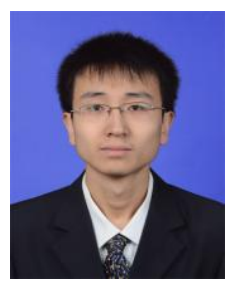

Xing Zhang was born in Liaoning Province, China, in 1991. He is currently working toward the B.S. degree in electrical engineering and automation at Northeastern University, Shenyang, China. His research interests include high-performance inverters and soft-switching techniques. 